\title{
Hardness analysis on carburized steel weld joint by SMAW using different welding current
}

\author{
Yanuar Rohmat Aji Pradana ${ }^{1, *}$, Wahono ${ }^{1}$, Dicky Tanzila ${ }^{1}$, and Azmi Lukman ${ }^{1}$ \\ ${ }^{1}$ Department of Mechanical Engineering, State University of Malang, 65145 Malang, Indonesia
}

\begin{abstract}
Low-cost weld joint on wear-resist gear train component was introduced for replacing conventional bolted connection to avoid its additional material and holes requirement. This study was concerned on the hardness analysis of carburized steel weld joint generated from SMAW with different welding currents, namely 80,100 , and $120 \mathrm{~A}$. The results indicated that the hardness is decreased at HAZ and subsequently increased at weld metal for all samples. On the other hand, the highest welding current applied during welding shows the highest hardness curve among the other currents up to $226.5 \pm 2 \mathrm{HV}$ at weld metal. By micro- and macrostructural analyses, phases evolution during thermal cycle on welding process played the crucial role to determine the hardness of HAZ, while the weld metal hardness was dominantly driven by the carbon-rich element distribution.
\end{abstract}

\section{Introduction}

Gear train is one of the important parts on automobile industries having crucial role to transmit the power from main driving component (engine) to output wheels mainly suffering from bending and contact loading, therefore, superior hardness is needed to induce sufficient surface wear resistance for withstanding continously contact with other transmission elements. Due to this condition, surface-hardened material is deserved to fulfill the surface requirement but still keep the internal ductility which could be achieved by carburizing on the metals, i. e. low carbon steel [1]. The gear trains are currently produced by bolt connection technique. This technique, however, requires additional joining components and space, as well as holes generation which making both materials and process cost remain higher. On the other hand, the total component weight is consequently increased due to additional bolt and nut weights, which is not desirable on today's automobile design due to the higher advance fuel consumption [2].

Lately, the application of laser welding was tried by many researchers to join the automotive components, such as differential gear $[2,3]$. This welding method is largely used due to its high energy density which possibly reduce the residual stress. The superior torsional stiffness performed on differential gear made from cast iron-carburized steel joint through laser welding compared with bolted connection was revealed by either simulation

* Corresponding author: yanuar.rohmat.ft@um.ac.id 
and experimental method on previous study [3]. However, the high cost of laser welding can limit its application in automotive industry of developing countries. On the other hand, the weldability of carburized steel having high carbon content is relatively low [4,5]. Furthermore, the characteristic of weld area is also affected by several driving forces generated from heat input and welding current in arc welding, as revealed by several studies [6-9]. Therefore, the welding parameter should be selected properly to maintain the similar hardness level between carburized base metal and the weld joint, so, the homogeineous wear resistance could be performed on entire component.

In this study, the performance of low-cost shilded metal arc welding (SMAW) for joining carburized steel was investigated for replacing bolted connection in gear train. To achieve the sufficient hardness on high-carbon-content steel weld joint, the various current densities were used through welding process for analyzing the evolution of joint hardness due to the reduction the grain size of weld metal as well as distribution of carbon from base metal surface to weldpool. The vickers hardness and microstructural analysis were conducted to investigate the effect of heat input on the hardness of carburized steel weld joint.

\section{Method}

The welding sample was prepared by carefully cut the low carbon steel (ST 37) plates with the thickness of $10 \mathrm{~mm}$. Subsequently, carburizing method was applied by using charcoal from coconut shell as carbon additive and barium carbonate $\left(\mathrm{BaCO}_{3}\right)$ as energizer, based on previous study [10-11]. The carburized steel plates was then welded through SMAW method using E7016 electrode with different welding currents, namely 80, 100, and $120 \mathrm{~A}$. The process was conducted for 3 passes and the welding speed was constantly controlled proportional to the selected current. Afterwards, the weld joint was gradually cut, polished, and etched to perform its cross-sectional view to distinguish the base metal, heat affected zone (HAZ), and weld metal. Both microvickers having load of $300 \mathrm{kgf}$ and $3 \%$ nital (3\% nitric acid in ethanol) were utilized for analyzing the hardness and etching the sample surface. The hardness test performed at the center of base metal, HAZ, weld metal. To ensure the hardness value, indentations was conducted 3 times for each analysis. The macroscopic view of weld cross-section were also provided by using digital camera.The weld microstructure was finally observed by optical microscope (OM) with 200 times of magnification.

\section{Results and Discussion}

After visually ensuring the weld joint was void-free and apropriate for further analysis, the hardness test was conducted at the center of base metal, HAZ, and weld metal area clearly distinguised by pre-etching, and the results indicates different both HAZ length and hardness value on weld joint generated by 80,100 , and $120 \mathrm{~A}$ of welding currents. The whole values were listed on Table 1 and performed on Figure 1. 
Table 1. Hardness test results of sample with different welding currents.

\begin{tabular}{|c|c|c|c|}
\hline \multirow{2}{*}{ Welding current (A) } & \multicolumn{3}{|c|}{ Hardness (HV) } \\
\cline { 3 - 4 } & Base metal & HAZ & Weld metal \\
\hline \multirow{3}{*}{20} & \multirow{2}{*}{$217 \pm 9.3$} & $172 \pm 2.8$ & $207 \pm 6$ \\
\hline 100 & & $180 \pm 3.8$ & $215 \pm 9$ \\
\hline 120 & & $186 \pm 5$ & $226.5 \pm 2$ \\
\cline { 4 - 4 } & & &
\end{tabular}
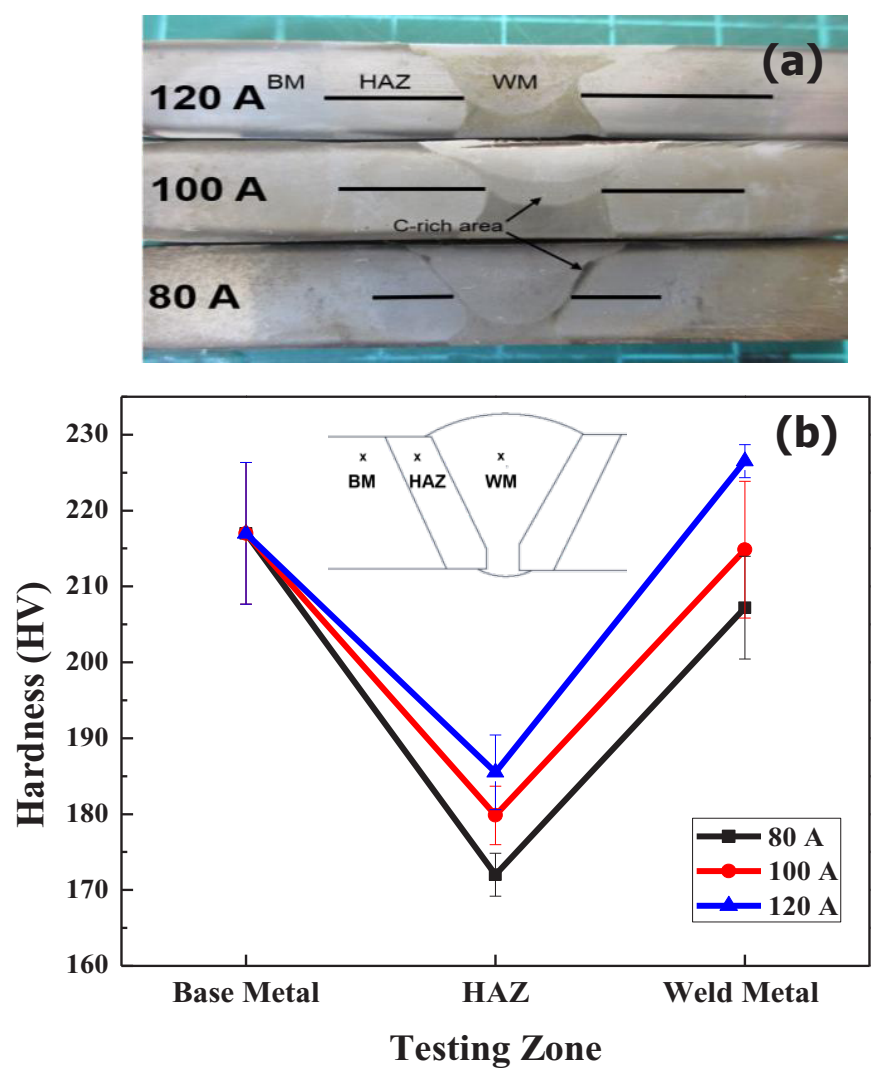

Fig. 1. (a) Cross-sectional view of weld samples performing HAZ and (b) hardness curves of sample with different welding currents.

The macrograph of cross-sectional view of weld samples performed on Figure 1(a) shows the typical larger HAZ area generated from higher welding current. Figure 1(b) performs the hardness results of samples welded using 80,100, and 120 A of welding currents, and the results indicates similar trend between each current. The relatively similar hardness value of base metal is determined to be $217 \pm 9.3 \mathrm{HV}$ and the reduction is observed on HAZ at all welding currents. Afterwards, the hardness is observed to be increased at weld metal. On the other hand, the higher welding current shift the hardness curve at a higher level for both HAZ and weld metal hardness. Moreover, by using $120 \mathrm{~A}$ of welding current, the hardness of weld metal reached the higher value $(226.5 \pm 2 \mathrm{HV})$ than its base metal counterparts. To clarify these phenomenon, the microstructural analysis using OM was conducted for each sample, and the results are performed on Figure 2. 

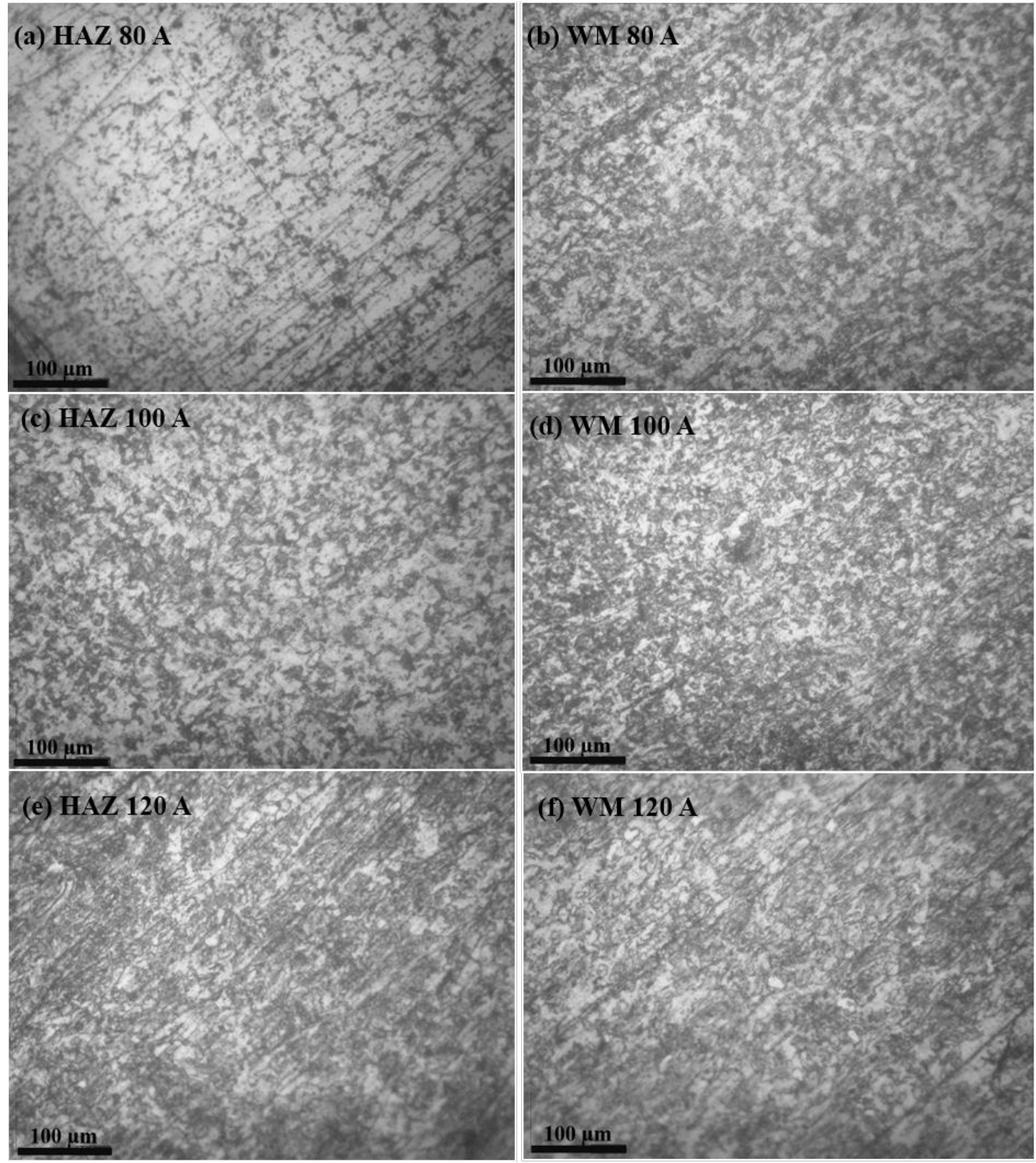

Fig. 2. Optical micrograph of weld joint for different welding currents observed at center of HAZ (a, c, e) and weld metal (b, d, f) using 200 times of magnification.

From Figure 2, it can be observed that the grain evolution were occurred by variying heat input using different current during welding. The larger grain is identified at HAZ area of 80 A sample implies that the hard martensite phase formed underneath the carburized layer after rapid cooling (quenching) step on carburizing treatment are re-heated during every pass of welding process and other softer phase was partially formed, thus generated the hardness reduction, not only for $80 \mathrm{~A}$ but also the other welding currents. Due to the lowest heat input given at $80 \mathrm{~A}$ welding current level, the peak temperature on HAZ was implied at the lowest point compared with other welding current. Consequently, the cooling rate gradient remains low giving the sufficient time for grain growth, therefore, the relatively large ferrite is observed, as shown on Figure 2(a). By increasing the welding current level up to $120 \mathrm{~A}$, the peak temperature of $\mathrm{HAZ}$ is increased making the greater 
cooling rate gradient, therefore, the smaller (Figure 2c) and or even sharper grain (Figure 2e) are noticed to be appeared indicating the presence of bainite phase which dominantly contributing the hard nature of steel $[12,13]$

Figure 2 (b), (d), and (f) show the microstructural view of weld metal of sample welded with 80,100 , and 120 A describing the development of dark area along with the increase of welding current. This indicates that the carbon distribution played an important role to determine the weld metal property. The higher carbon contained on original sample surface distributed to the weld metal by higher current during welding process. Due to the higher carbon content, the hardness of weld metal is improved. To evidence this fact, 80 A sample was selected to be further analyzed by macrostructure method due to its clear carbon-rich zone traces resulted by sluggish stirring/convection movement during welding introduced by by lorentz, buoyancy, and marangoni force at low welding current $[4,6,7]$. The etched weld surface of $80 \mathrm{~A}$ samples is performed on Figure 3 below.

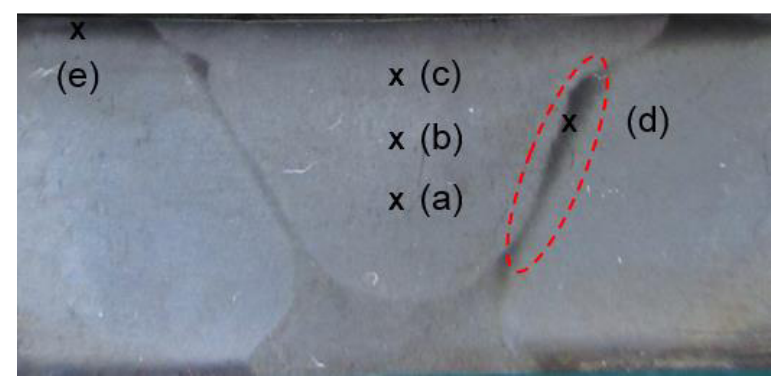

Fig. 3. Macrograph of weld joint on $80 \mathrm{~A}$ sample showing carbon-rich zone in dark area.

Table 2. Hardness test results of selected point on 80 A sample.

\begin{tabular}{|c|c|c|c|c|c|}
\hline Zone & Center (a) & Near-top (b) & Top (c) & Dark zone (d) & $\begin{array}{c}\text { Carburized } \\
\text { layer (e) }\end{array}$ \\
\hline $\begin{array}{c}\text { Hardness } \\
\text { (HV) }\end{array}$ & $252 \pm 10$ & $224 \pm 3.5$ & $207 \pm 6$ & $336 \pm 18$ & $364 \pm 4$ \\
\hline
\end{tabular}

From Figure 3, the dark signal indicates the carbon-rich zone left after welding process because of both less-sufficient stirring force and melting heat generated by low current. The hardness distribution test is then conducted from the center of welding centerline to the top of weld metal, as demonstrated on Figure 3. The results are listed on Table 2.

From the Table 2, it is clear that both of stirring force and heat generated during welding has crucial role to determine the hardness property of weld metal. Both dark zone (d) indicating carbon rich-zone from original carburized surface and the center of carburized layer show the hardness of $336 \pm 18$ and $364 \pm 4 \mathrm{HV}$, respectively. The reduction of hardness along center to the weld metal surface (point a, b, and c), that are $252 \pm 10$; $224 \pm 3.5$; and $207 \pm 6 \mathrm{HV}$, respectively, indicates the limitation of driving force to distribute the carbon-rich element to the top of weld pool during the welding process, therefore, the carbon-rich element still remain at the deep position of weld metal, and consequently lowhardness weld surface was produced. Furthermore, to introduce the better carbon distribution from base metal carburized surface to entire area of weld metal and finally improve the weld surface hardness, high welding current should be applied.

\section{Conclusion}

Based on the study succesfully conducted on ST 37 carburized steel weld joint after joining process by SMAW, it can be concluded that the phases evolution during thermal cycle on 
welding process played the crucial role to determine the hardness of HAZ where the higher heat input generated higher hardness of HAZ. Contrary, the weld metal hardness was dominantly varied by the carbon-rich element distribution resulted from original carburized sample surface. By using high welding current, the carbon was well distributed by sufficient stirring force to the entire weld metal and can reach the higher near-tip hardness of $226.5 \pm 2$ at 120 A of welding current compared with the base metal (217 \pm 9.3 ), therefore, higher welding current selection can be considered to enhance the weld hardness.

\section{References}

1. P. Zhang, F. C. Zhang, Z. G. Yan, T. S. Wang, and L. H. Qian, Wear, 271, pp. 697-704 (2011)

2. Z. Linjie, Z. Jianxun, H. Kalaoui, H. Li, and Y. Wang, J. Mater. Process. Tech., 190, pp. 109-116 (2007)

3. J. Yu, T. Jung, S. Kim, and S. Rhee, J. Mech. Sci. Tech., 25, 11, pp. 2887-2893 (2011)

4. S. Kou, WELDING METALLURGY SECOND EDITION (2003)

5. K. H. Kim, I. J. Moon, K. W. Kim, K. B. Kang, and B. G. Park, K. S. Lee., J. Mater. Sci. Tech., 33, 4 (2017)

6. J. Zhou and H. Tsai, Int. J. Heat Mass Transfer, 50, pp. 2217-2235 (2007)

7. M. A. Garcia-Renteira, V. H. L. Moreloz, J. G. Sanchez,., R. G. Hernandez, and F. F. C. Lopez, Appl. Surf. Sci., 396, pp 1187-1200 (2017)

8. A. K. Singh, V. Dey, and R. N. Rai, Mater. Today Proc., 4, 2, pp. 1252-1259 (2017)

9. R. Chen et al., J. Mater. Process. Tech., 247, pp 306-314 (2017)

10. H. Suryanto, Malang State University. (2017)

11. S. A. Afolalu, E. H. Asonaminasom, S. O. Ongbali, A. A. Abioye, M. O. Udo, and E. Y. Salawu, Data in Brief. 19, pp. 2279-2283 (2018)

12. J. Carlos et al., J. Mater. Res. Tech., xx, pp. 1-11 (2018)

13. H. Alipooramirabad, A. Paradowska, R. Ghomashchi, and M. Reid, J. Man. Process., 28, pp. 70-81 (2017) 